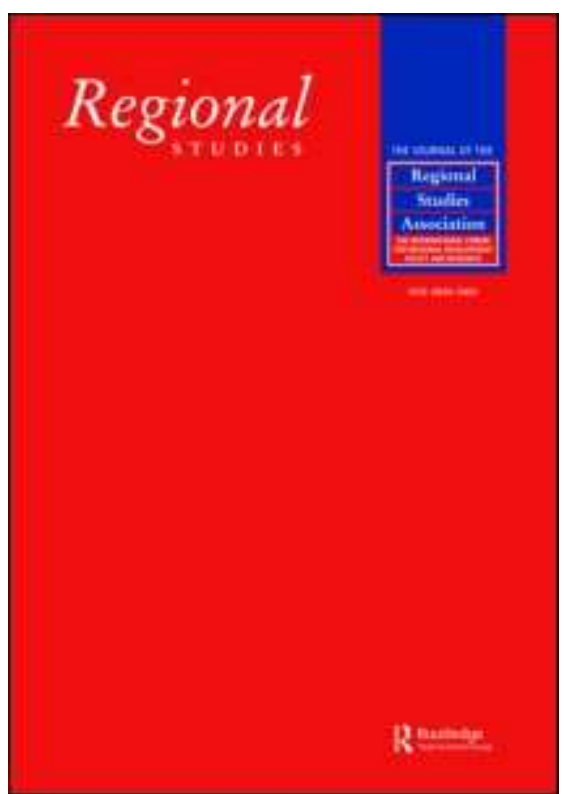

\title{
Spatially concentrated deprivation in England: an empirical assessment
}

\begin{tabular}{|c|l|}
\hline Journal: & Regional Studies \\
\hline Manuscript ID: & CRES-2010-0335.R1 \\
\hline Manuscript Type: & Main Section \\
\hline JEL codes: & $\begin{array}{l}\text { J0 - General < J - Labor and Demographic Economics, J40 - General } \\
<\text { J4 - Particular Labor Markets < J - Labor and Demographic } \\
\text { Vacancies < J - Labor and Demographic Economics, J64 - } \\
\text { Unemployment: Models, Duration, Incidence, and Job Search < J6 - } \\
\text { Mobility, Unemployment, and Vacancies < J - Labor and } \\
\text { Demographic Economics }\end{array}$ \\
\hline Keywords: & $\begin{array}{l}\text { deprivation, poverty, disadvantage, spatial, concentration, labour } \\
\text { market area }\end{array}$ \\
\hline
\end{tabular}

\section{SCHOLARONE \\ Manuscripts}


Spatially concentrated deprivation in England: an empirical assessment

\author{
Alasdair Rae \\ Department of Town and Regional Planning \\ University of Sheffield \\ Sheffield \\ S10 2TN \\ United Kingdom
}

a.j.rae@sheffield.ac.uk

(Received October 2010: in revised form February 2011) 


\begin{abstract}
Spatially concentrated deprivation is a well documented phenomenon and is of interest to a diverse constituency of academics and policy makers. Despite the accepted view of concentrated deprivation as a problem, however, the empirical basis for understanding it remains under-developed. Therefore, an attempt is made here to provide an empirical assessment of spatially concentrated deprivation in England, using spatial statistics and a policy-relevant deprivation measure. More localised analyses are also conducted for London, Birmingham, Liverpool and Manchester. The results demonstrate that deprivation in England is highly concentrated, that it varies significantly over space and that spatial patterns persist through time.
\end{abstract}

Keywords: deprivation, poverty, disadvantage, spatial, concentration, labour market area

JEL Codes: J0 - General < J - Labour and Demographic Economics, J40 - General $<\mathrm{J} 4$ - Particular Labour Markets < J - Labour and Demographic Economics, J60 General < J6 - Mobility, Unemployment, and Vacancies < J - Labour and Demographic Economics, J64 - Unemployment: Models, Duration, Incidence, and Job Search < J6 - Mobility, Unemployment, and Vacancies < J - Labour and Demographic Economics 


\section{Introduction}

The phenomenon of spatially concentrated deprivation has interested policy makers and academics for many years and has resulted in a wide variety of different interventions which attempt to combat its perceived ill-effects. The reason why spatially concentrated deprivation is seen to be problematic is often linked to arguments for the existence of 'area' or 'neighbourhood' effects (GALSTER et al., 2007), whereby the impact of larger areas of poverty are seen to adversely affect life chances above and beyond individual characteristics (SAMPSON, 2003). Despite seemingly powerful arguments against the importance, or strength, of the neighbourhood effect (e.g. CHESHIRE, 2007; VAN HAM and MANLEY, 2010), however, it has become commonplace for governments in many nations to employ social mix strategies in order to break up (or dilute) large concentrations of deprivation, poverty or disadvantage (e.g. GALSTER, 2007). Beyond the neighbourhood effects issue, there are of course more fundamental questions of spatial justice associated with concentrations of deprivation (DABINETT, 2010).

Notwithstanding wider concerns about why policy focuses almost exclusively on concentrated poverty rather than, or as well as, concentrated affluence (MASSEY, 1996; COULTON et al., 1996) there remains a lack of empirical evidence in relation to the scale of the phenomenon and the extent to which the spatial concentration of deprivation may change over time. Even where commentators disagree about the importance of the neighbourhood effect on individual outcomes, the existence of concentrated deprivation, particularly in inner-urban locations, is not debated. With very few exceptions (e.g. GALSTER, 2005; DORLING et al., 2007; OAKLEY and LOGAN, 2007), an empirical basis for understanding this concept is lacking. Within the contemporary 'evidence-based' policy paradigm it is non-existent. This is an 
important shortcoming, since policies which seek to foster a more mixed society involve significant public expenditure and have enjoyed widespread support. If there is no real objective basis for measuring concentration then the kinds of policies currently and recently in operation cannot, in the contemporary fiscal climate, be easily justified - even if they appear to be effective. This research therefore seeks to take a step back from wider debates about social mix strategies and neighbourhood effects (e.g. DARCY, 2007; LUPTON and FULLER, 2009) in order to provide the kind of spatial intelligence which can help policy makers and academics understand the geography, intensity and persistence of the spatial patterns which motivate intervention in the first place. This is done by presenting a series of empirical findings on patterns of concentrated deprivation in England.

There are four sections in this paper, followed by some concluding remarks. The first section briefly introduces and explores the theoretical lineage and contemporary policy context behind the concept of spatially concentrated deprivation in order to foreground the subsequent empirical analysis. The second section considers the analytical background to the analyses which follow and provides further details of the specific dataset used. The third section reports on the empirical research undertaken. It presents a series of more in-depth findings relating to the nature of spatially concentrated deprivation in England on an annual basis from 1999 to 2005 - an important time period in the recent history of English urban policy. This is first done at a national level, with a subsequent focus on four key urban areas. The evidence presented here is based on comprehensive spatial statistical analysis. A fourth section then attempts to draw together the findings and focus on key messages emerging from the foregoing empirical section. 


\section{Understanding Spatially Concentrated Deprivation}

In addition to concentrated deprivation, socio-spatial inequalities are often approached from two related perspectives, with some authors focusing on concentrated 'disadvantage' (e.g. CARPIANO et al., 2009) and others on concentrated 'poverty' (e.g. LUPTON and FULLER, 2009). Although these concepts overlap in many aspects and distinctions are sometimes difficult to make, there are important definitional differences which mean they cannot be treated as entirely synonymous in an empirical study - even if policy responses to each are similar. Spatially concentrated poverty is typically operationalised in relation to the percentage of people in an area who are in 'poverty', according to some nationally contextualised median household income value (e.g. GALSTER, 2005). Spatially concentrated disadvantage, on the other hand, is a more relative concept, which can be applied to different groups in different ways (e.g. NATION, 2008) and can also be extended to incorporate the more generic construct of 'locational disadvantage' (DARCY, 2007). The term 'deprivation' is adopted here since the data used are part of an official deprivation index relating to 'economic deprivation' in England (CLG, 2009) and the results relate specifically to spatial concentrations in this sense. The initial sections of this paper recognise the overlaps between deprivation, poverty and disadvantage - particularly in relation to policy responses - whereas the empirical sections relate specifically to the concept of 'deprivation' as defined by the Economic Deprivation Index (CLG, 2009).

The spatial clustering of poverty, disadvantage or deprivation is not a new phenomenon; a fact noted by numerous commentators (e.g. JONES, 1979; GALSTER, 2005; NORTH and SYRETT, 2008). Concomitantly, neither is the idea that such clustering is a problem and that more balanced communities are a solution 
(e.g. LUPTON and FULLER, 2009). Nonetheless, over the past fifteen years in particular there has been something of a re-invigoration of attempts to do something about spatially concentrated deprivation, and its presumed pernicious effects. This has come to fruition in a number of countries and by means of a variety of quite different urban policy interventions. Examples include the much-cited 'Moving to Opportunity' experiment in the United States (GOERING and FEINS, 2003) and the more broad-brush 'Big Cities Policy' in the Netherlands (VAN KEMPEN and BOLT, 2009). In England, the New Deal for Communities programme (LAWLESS, 2004) and its contemporaries were symbolic of the New Labour 'urban renaissance' project and an ideological commitment to a form of spatial and social justice. The literature on this topic is now voluminous and rightly critical since the results now seem at odds with the rhetoric. The intention here, though, is to consider how spatial concentration has been approached and understood in relation to the associated phenomena of deprivation, poverty and disadvantage, and to highlight the lack of empirical evidence in relation to the precise nature of concentrated deprivation as it is currently conceptualised.

One of the less well noted features of recent literature on concentrated deprivation, poverty or disadvantage is the extent to which the phenomena remain, in spatial empirics, somewhat ill-defined. This is in contrast to their identification as phenomena per se (e.g. SAMPSON et al., 1997; COHEN et al., 2003; NATION, 2008; CARPIANO et al., 2009). Thus, important contributors such as NORTH and SYRETT (2008) accurately describe the problem of concentrations of deprivation with reference to spatial patterning across England at a moment in time, but do not measure it in a spatial statistical manner. This is not a problem in itself, of course, but if we are to understand the impacts of policy intervention on concentrated 
deprivation through time and space it is useful to have some reference point from which to begin, hence this research. First, however, it is important to have some understanding of how it has been conceptualised and how this has fed into the policy mainstream, if at all.

In the wide-ranging literature that spans the social sciences, there are many different perspectives on the problem of spatial concentration; this can be seen in relation to studies on deprivation (RAE, 2009), poverty (GALSTER, 2005) and disadvantage (CARPIANO et al., 2009). However, it is possible to identify four relevant, inter-related themes here. First, we have the fundamental capitalistic uneven development thesis, propagated most powerfully by David Harvey (e.g. HARVEY, 1985), which views the geographical nature of deprivation as an artefact of the spatial manifestation of capitalism. In this view, spatial concentration is a symptom rather than a cause of social disadvantage. Related to this "concentration as symptom' stance, there is a second view of concentration as something of a distraction in wider debates on poverty and place. In this view, commentators have either highlighted the inherent limitations of contemporary policy (CHATTERTON and BRADLEY, 2000) or highlighted a lack of justification for mixed community policies in the first place (CHESHIRE, 2007). Very different intellectual traditions here lead to similar conclusions (cf. LUPTON and FULLER, 2009). Third, there is the view of spatial concentration as a remnant of historical-geographical processes which consume space differently at different times (cf. MASSEY, 1979). In this perspective, it is longer-term macroeconomic and macro-spatial forces which are given primacy, and policy solutions are not necessarily spatial. A fourth element emerging from the literature is the tendency to focus on spatially concentrated deprivation, poverty or disadvantage as isolated phenomena so that concentrated 
affluence largely remains unchallenged (see MASSEY, 1996; SAMPSON et al., 2002). This remains one of the most surprising aspects of the subject matter; particularly in disciplines which contain so many critical voices. Given these factors, and the potency of their central arguments, one might expect policy responses to socio-spatial inequalities to encompass a wide range of different measures, including macro-economic stimulus and public transport investment. Instead, the promotion of 'social mix' strategies (e.g. ARTHURSON, 2002) has dominated and one is left to question if there is actually a serious disconnect between theory and practice here.

In his paper on the need for a more reflexive epistemology in spatial social science, DARCY (2007) notes that in contemporary public housing policy discourse, 'concentration of disadvantage' has been identified as the problem and 'social mix' presented as the solution. Similarly, GALSTER (2007) comments on the adoption of such strategies by several western European countries, and DUYVENDAK et al. (2009) comment on the commitment to, but differences in, social mix strategies between the US and France on the one hand and the Netherlands and UK on the other. Given this explicit focus on concentrated deprivation, poverty or disadvantage as a problem, and the culture of evidence-based policy which predominates, then, it is reasonable to expect that any policies implemented would have some basis for assessing empirically the extent, nature and trajectory of spatial concentration. But this is not the case. There have been studies which explore this issue in various ways (e.g. DORLING et al., 2007; PATACCHINI and RICE, 2007) and attempts to 'spatialise' existing attributional measures of deprivation at a local level (RAE, 2009), but spatially concentrated deprivation remains a somewhat opaque concept in a formal sense. We know that it exists, that it is important and that it persists through time, yet we do not formally assess its intensity, its trajectory or its scale. Given the 
raft of policy measures which seek to reduce the impact of concentrated deprivation, and the availability of spatial statistical tools, it seems opportune now to offer new analysis. The next section of the paper therefore presents the analytical details of the approach and provides details of the dataset used.

\section{Analytical Background and Methods}

Differing geographical patterns of deprivation, poverty and disadvantage are well documented within a variety of national contexts, most notably for urban areas of the United States (e.g. DANZIGER and GOTTSCHALK, 1987; BROADWAY, 1989: MASSEY and EGGERS, 1993). Measures of spatial concentration of different phenomena are also well documented, and particularly so in the field of spatial economics (e.g. BRÜLHART and TRAEGER, 2005), yet applications in analyses of concentrated deprivation remain under-developed. There are some notable exceptions to this (e.g. LORANT et al., 2001; SRIDHARAN et al., 2007), but they tend to focus on health outcomes at the local level. Two particularly insightful studies (ORFORD, 2004; DORLING et al., 2007) do offer a more comprehensive approach to understanding concentrated deprivation and changes over time, but such methods have not yet connected with the policy mainstream, despite a growing awareness of the importance of 'place' more generally (CLG, 2007). Orford's 2004 study in particular highlights the persistence of concentrated deprivation in London since 1891, thereby emphasising the magnitude of the policy challenge. The intention of the analysis developed here, then, is to build upon the work of others by more formally exploring patterns of spatially concentrated deprivation in England through a data series which includes seven consecutive years (1999-2005), using a standardised deprivation index. In addition to highlighting spatial variation within the 
dataset, it is also useful to explore the extent to which patterns change year on year, even over relatively short time periods. This can provide additional information on the spatio-temporal volatility of concentrated deprivation, in contrast to a single year 'snapshot' analysis.

In spatial statistical analyses there are a number of different approaches to measuring concentration, some of which are not truly geographical (e.g. the Gini coefficient) and some of which allow for the specification of spatial weights matrices to define spatial relationships, like Geary's c (see CLIFF and ORD, 1970). Such measures have been used at length to analyse the spatial clustering of activity, and have often been extended and adapted in order to evaluate formally the spatial distribution of firms (e.g. MARCON and PUECH, 2003). Of the truly geographical measures of concentration, there are a number of feasible alternatives one can use to analyse the spatial clustering of deprivation, with Geary's $c$ and Moran's I being the most well known and of comparable robustness (see ORFORD, 2004). However, Moran's $I$ is often preferred because the significance test has been deemed more reliable (MITCHELL, 2005). Therefore, the results presented below are based on the use of the Moran's I measure of spatial concentration in relation to deprivation in England. Like Geary's $c$, this statistic can be computed using applications such as ArcGIS, GeoDa and $R$ and can be interpreted in a manner similar to the product moment correlation coefficient. When areas with similar values are clustered, Moran's I approaches 1.0. When areas with dissimilar values are found next to each other in a chess board type pattern, Moran's I approaches -1.0. A pattern of perfect spatial randomness would yield a Moran's I value close to zero. In addition to the Moran's I analysis, further analysis using related techniques was also completed at the local level. The Local Moran's I method (ANSELIN, 1995) provides further 
empirical evidence relating to the extent to which individual areas may contribute to the 'global' values generated by the initial Moran's I analysis'.

When it comes to the measurement of deprivation, as it is most commonly approached in England, a number of competing measures have historically been used for different purposes (e.g. CARSTAIRS and MORRIS, 1991), and developed within specific policy contexts (e.g. CLG, 2007). Such indices are comprised of a number of subordinate indicators which, when combined, provide a relative measure of deprivation for each area for a fixed time period, typically at a local level such as a census tract or ward. These indices have been critiqued on a number of fronts (e.g. DEAS et al., 2003) and typically do not allow for analysis between time periods, but they remain an important part of 'official' and 'unofficial' assessments of local areas in the identification of deprivation and need in different parts of the world (PAMPALON and RAYMOND, 2000; MESSER et al., 2006; REY et al., 2009; NOLAN and WHELAN, 2010). Therefore, the analysis carried out below represents a continuation of an analytical tradition which transcends disciplinary boundaries and seeks to contribute to a growing literature on the spatial nature of deprivation, poverty and disadvantage. Further details of the specific dataset used are now provided.

In England the Indices of Deprivation are the de facto measure of deprivation used to determine, among other things, funding allocations for policy interventions. The most recent version was published in 2007 (CLG, 2007), and a comparable version was previously published in 2004 (ODPM, 2004). However, one of the main issues with the Index is backward comparability, as noted by the central government department responsible for producing it: 'The one disadvantage of the quest to have the Indices of Deprivation as the best measure for their time is that 'backwards 
comparability' and the construction of a time series is compromised (CLG, 2009, 7)'. As a result, a new, complementary, deprivation index for tracking neighbourhoods through time was produced. This Economic Deprivation Index (EDI) has, at the outset, provided users with a data time series at small area level ${ }^{2}$ from 1999 to 2005 inclusive. It allows users, for the first time, to track changes in the nature, spatial extent and clustering of deprivation at a national level in England. It is comprised of two separate data domains ('income deprivation' and 'employment deprivation') which are themselves included in the more wide-ranging Indices of Deprivation. Further details of the composition and construction of the EDI are available elsewhere (CLG, 2009) but, in short, the income deprivation element of the EDI includes low income residents, defined as those people aged under 60 living in households that receive either Income Support or income-based Jobseekers Allowance. The employment deprivation element of the EDI includes people of working age who are involuntarily excluded from the labour market due to unemployment or ill health (see also CLG, 2010). For each Lower Layer Super Output Area (LSOA) in England a deprivation score is calculated, with the least deprived areas having values close to zero and the most deprived having values approaching 100. All 32,482 LSOAs in England are ranked according to this score in order to allow for further comparative analysis. The results of the analysis using the chosen method of spatial autocorrelation (Moran's I) and the English EDI are now presented, moving from a national to local level.

\section{Data analysis for England, 1999-2005}

The existence of spatially concentrated deprivation in England is well documented (e.g. JONES, 1979; BRENNAN et al., 2000) and is a widely accepted 
phenomenon. Less well documented is the precise nature of this concentration, its variation through time, and its spatial variability. Where studies of this kind do exist they do not make a connection between measures of deprivation used in policy formulation and spatial statistical measures of concentrated deprivation. This is attempted here in order to give the concept a more rigorous statistical underpinning and to provide useful policy intelligence at the national level in England. In doing so, the first task is to provide a general overview of the spatial patterns associated with deprivation in England, as identified by the Economic Deprivation Index, using a measure of spatial autocorrelation. This first part is supplemented by local spatial autocorrelation methods in order to gain a better understanding of the local contexts of deprivation in existence. In order to provide additional depth to the research, further analyses are conducted for four of the most deprived areas in England, using both global and local measures of spatial autocorrelation.

\section{National Patterns of Spatially Concentrated Deprivation: An Overview}

In Figure 1 the national pattern of economic deprivation in England (as defined by the Economic Deprivation Index) is shown for the most deprived decile of LSOAs in 1999, in addition to the least deprived decile. Although the intention in this paper is not to focus on the identification of concentrated affluence, it is of course a corollary of concentrated deprivation so it is useful in the first instance to provide a spatial overview of both. A notable feature of the spatial pattern identified here is the close correlation between the urban footprint of England and the location of the most deprived areas. Conversely, there is also a close spatial correlation between the least deprived areas and more rural locations. However, such conclusions can be misleading since they may mask important local variations in deprivation and they 
may also be a function of the larger geographical units typically found in rural areas. Thus, it is more useful to consider statistically the extent to which deprivation is concentrated, rather than to focus on visual patterns.

Following RAE'S (2009) first order contiguity conceptualisation of spatial relationships for LSOAs across England ${ }^{3}$, the Moran's I values for the EDI were calculated for each year from 1999 to 2005. These are presented in the form of global Moran scatterplots in Figure 2. These scatterplots visualise the type and strength of spatial association in a data distribution (see ANSELIN et al., 2004), with standardised data variables on the $\mathrm{x}$-axis (EDI Score) and standardised values of neighbouring locations on the $y$-axis ( $\left.N \_E D I S C o r e\right)$. There is a strong positive trend of spatial concentration of deprivation in England. This deviation from spatial randomness is consistently strong and statistically significant ${ }^{4}$ through time, though there is a decrease in Moran's I, from 0.6195 in 1999 to 0.5838 in 2005 . These findings are similar to those in earlier work by DORLING et al. (2007) for poverty in Great Britain, and of ORFORD (2004) in Inner London, and in many ways confirm what is already known about such patterns. What is new here, however, is empirical evidence which specifies the degree of spatial concentration for an 'official', policyrelevant deprivation index and which highlights an apparent, though modest, trend for such concentration to reduce through the seven year data series. This last finding is also consistent with trends identified by DORLING et al. (2007, 37), though over a shorter time frame.

\title{
Figure 1 about here
}

\author{
Figure 2 about here
}


National Patterns of Spatially Concentrated Deprivation: A Contextual Analysis

National spatial patterns of deprivation are worthy of attention, since they are able to place in national context any variation between areas. However, these general patterns do not say much at all about the spatiality of deprivation within localities, how it is structured or where the greatest concentrations exist. For this purpose, the EDI data series was subjected to further analysis using a more finegrained analysis (ANSELIN, 1995). Whereas the global Moran's I figures presented above are indicative of significant clustering of deprivation, local indicators of spatial association (LISA) are able to test for the presence of spatial clusters (sometimes referred to as hot spots) within an entire dataset. Such analyses have become more common in recent years (e.g. OAKLEY and BURCHFIELD, 2009) as awareness of the importance of location and spatial context has grown in line with an expanding toolset which includes spatially sensitive applications such as $R$ (EVERITT and HOTHORN, 2006), GeoDa (ANSELIN, 2003) and the Geospatial Modelling Environment (BEYER, 2010). Local methods of analysis allow us to go beyond the question of whether deprivation is concentrated to ask, precisely, where it is concentrated and how it is concentrated. The answers provided give greater depth to spatial analyses and allow us, in essence, to deconstruct global spatial autocorrelation statistics such as Moran's I so that we can identify the locations where concentration is strongest.

Following methods available in Anselin's GeoDa, the first stage in understanding more about the local contexts of concentrated deprivation was to apply a spatial statistical categorisation to the EDI data using LISA. The benefit of this approach is that it produces a robust categorisation of all areas within a dataset, according to the 
extent to which they are surrounded by statistically similar or dissimilar areas. In this instance, the conceptualisation of spatial relationships was restricted to first order contiguity so that areas were categorised according to the value of immediately contiguous areas only. In line with similar research conducted previously (e.g. RAE, 2009) this was found to be the most suitable specification of 'local' areas. Once the LISA categorisation is applied and the corresponding significance values calculated, each LSOA is assigned to one of five categories, as below. These categories correspond to different quadrants of the global Moran scatterplot (see Figure 3) and are identified according to a default significance value of $p=0.05$, as described in ANSELIN et al., 2004. Not every area meets the significance criteria, but those that do conform to the quadrant pattern identified here.

- 1 'High-High' - a LSOA with a high EDI score is surrounded by LSOAs with similarly high EDI scores (top right quadrant in Figure 3);

- 2 'Low-Low' - a LSOA with a low EDI score is surrounded by LSOAs with similarly low EDI scores (bottom left quadrant in Figure 3);

- 3 'Low-High' - a LSOA with a low EDI score is surrounded by LSOAs with high EDI scores (top left quadrant in Figure 3);

- 4 'High-Low' - a LSOA with a high EDI score is surrounded by LSOAs with low EDI scores (bottom right quadrant in Figure 3); and

- 0 'Not Significant' - a LSOA does not exhibit any statistically significant relationships with surrounding LSOAs.

\section{Figure 3 about here}


Table 1 shows the results of this analysis for England. There is little variation between years for the percentage of people living in LSOAs which are "not significant' in terms of their spatial context on the EDI. Nonetheless, around $15 \%$ of persons in England live in LSOAs which are classified as having a high deprivation score and surrounded by LSOAs with similarly high deprivation scores. What is perhaps more surprising here, given the continued focus on concentrated deprivation rather than affluence, is the level of spatial clustering among areas with low deprivation scores. Around a quarter of residents in England live in such areas. Areas which are less deprived but surrounded by more deprived areas account for around $1.5 \%$ of the entire population, whereas areas of high deprivation with less deprived neighbours account for around $1.0 \%$ of the population.

\section{Table 1 about here}

Although the data presented in Table 1 are useful on many levels, and highlight a degree of consistency through time, they are subject to a phenomenon which we might term 'macro-spatial relativity'. That is, the identification of a 'highhigh' LSOA classification in one local area may actually be based on a relatively low deprivation score nationally. Similarly, each of the other categories may suffer from this phenomenon depending upon their local spatial context. In order to provide further information here, Figure 4 displays each LISA cluster category according to the EDI score from 2005 (other years yield very similar results, so the most recent is used here). We observe that some of the areas in the high-high deprivation category (1) have rather low deprivation scores and are certainly not the types of areas usually targeted by policy interventions. The same is true of those in the high-low 
category (4). It is useful in the first instance to highlight this macro-spatial relativity since it provides further insights into the way in which the LISA approach, though robust, must be treated with caution in such analyses. When conducting analyses of concentrated deprivation, it is necessary to apply the LISA categorisation only to those areas which can justifiably be described as 'deprived', according to some cutoff figure.

In order to focus in on those areas which exhibit the characteristics of statistically significant spatial clustering and high deprivation scores, only LSOAs from the most deprived EDI decile are shown in Figure 5. These LSOAs accounted for $9.89 \%$ of the English population in 2005 ; a total of nearly 5 million people. Of this total, $30.7 \%$ live in areas which are not neighboured by statistically significant similar or dissimilar areas, $69.1 \%$ live in high-high LSOAs and $0.2 \%$ live in high-low LSOAs. At a national level, then, this adds additional spatial intelligence to what we already know about geographically concentrated deprivation in England. Each of these three different types of area is likely to receive policy attention, but the kinds of intervention required may differ depending upon their wider spatial contexts. As a supplement to this final piece of national level analysis, it is also useful to compare the individual local Moran's I values for LSOAs to their original EDI score to examine the relationship between degree of deprivation and degree of local spatial concentration. A larger positive value for local Moran's I indicates that a feature is surrounded by features with similar attributes (MITCHELL, 2005, 167) and in Figure 6 we can observe a pattern whereby the most deprived LSOAs in England are also the most clustered, in spatial statistical terms. This then leads to questions regarding the precise locations of the largest areas of concentrated deprivation and their characteristics. The next section explores this in more detail. 


\section{Figure 4 about here}

\section{Figure 5 about here}

\section{Figure 6 about here}

\section{Local Patterns of Spatially Concentrated Deprivation}

The national patterns presented above form an important part of understanding the nature of spatially concentrated deprivation and its subsequent interpretation in policy settings. However, the determinants of the phenomenon being measured (economic deprivation) are best contextualised at a scale below the national level, in line with long-established knowledge on the most appropriate areal units for analyses on such topics (e.g. COOMBES et al., 1988). It is also the case that concentrated deprivation is more concentrated in some locations than it is in others. This is particularly true in England, where northern cities, and London, dominate the most deprived decile and, correspondingly, the urban policy agenda. Therefore, this analysis will now move down a scale to consider concentrations of deprivation within their labour market contexts, here approximated to the most recent travel-to-work area (TTWA) boundaries (COOMBES and BOND, 2008), as shown in Figure 7.

Within England, the labour market areas with the highest absolute number of deprived residents are London, Birmingham, Liverpool and Manchester. In proportional terms, three of these areas also have a higher than average percentage of residents who live in areas classified as being amongst the $10 \%$ most deprived 
according to the EDI (see Table 2). Given these facts, and their relative importance within a national context, it was deemed appropriate to conduct further analysis in these areas, in order to measure the degree of concentrated deprivation in evidence locally. Analysis for other labour market areas was also carried out during the research and, where relevant, data on these are also presented. However, for the purposes of understanding more localised patterns of deprivation in their individual labour market contexts, these four locations serve as useful examples.

\section{Figure 7 about here}

\section{Table 2 about here}

This initial overview in many ways confirms what is already known about the geography of deprivation in England but it does add a new dimension in terms of contextualising this within appropriate labour market geographies and providing an empirical baseline. What is more instructive here is to explore the extent to which deprivation is concentrated within each of these areas and to compare these data to the national picture, presented above. First, the global Moran's / statistic was calculated for each labour market area before local indicators of spatial association were computed, in order to provide a spatially-relevant understanding of patterns within the context of each local area. This was performed for each year of the EDI data series in order to track changes in spatial composition through time.

In Table 3 the results of the global spatial autocorrelation analysis are shown for each of the four TTWAs. In each area, there is strong evidence of spatial clustering of LSOAs with similar deprivation scores, much like the general patterns 
for England described above. However, it is important to exercise caution when making comparisons on the degree of spatial autocorrelation between areas since, as several contributors have shown, scale effects may have a significant impact on spatial analyses (e.g. GREEN and FLOWERDEW, 1996). This does, of course, relate to wider issues associated with the modifiable areal unit problem and the variability of results at different spatial scales (e.g. OPENSHAW and TAYLOR, 1979), so the analysis here remains fixed at LSOA level. An area ripe for future research is therefore the impact of zonal classification on the results of spatial statistical analyses of concentrated deprivation, poverty and disadvantage (cf. FOTHERINGHAM and WONG, 1991). Given these issues, the comparisons being made here are between different years in each TTWA.

Between 1999 and 2005 the degree of spatial clustering areas with similar deprivation scores decreased, though in all cases it remained high and statistically significant. This trend of decreasing concentration is most obvious in Manchester, where the Moran's / statistic decreased from 0.5850 in 1999 to 0.5267 in 2005. In each year of the time series, the spatial concentration of deprivation is lower in the Manchester TTWA than it is across England as a whole. Whilst these two figures are not directly comparable, the decrease in Moran's / in both cases may an important finding in light of the kind of 'mixed communities' initiatives in operation during the time period (LUPTON and FULLER, 2009). In Birmingham and Liverpool, by contrast, the degree of spatial concentration is higher and does not follow the same downward trajectory, though the values do decrease slightly over time. Despite these decreases the degree of spatial clustering remains very high and nearly matches the values for Hull, the TTWA with the highest degree of spatial concentration in England, with a Moran's / value of 0.666 in 1999 and 0.6714 in 2005. Other areas 
one might expect to exhibit similarly high figures do not display this degree of concentration, as the 2005 Moran's I values for Newcastle and Durham TTWA (0.4727), Hartlepool TTWA (0.3762), Stoke TTWA (0.4517) and Doncaster TTWA (0.3306) attest.

\section{Table 3 about here}

Having established the degree of spatial concentration of deprivation within each labour market area, the next stage of the analysis involved implementing the LISA categorisation for each TTWA. In line with the national-level analysis above, this was performed for all areas in each TTWA. Those LSOAs which fell within the most deprived decile on the EDI within England as a whole are summarised by LISA category in Table 4. In each case except London all areas fall into either the 'not significant' category or the 'high-high' category. In all cases, the percentage of residents living within areas classified as 'high-high' is greater than the 'not significant' category. In London, this represents about $7 \%$ of the total population, which in 2005 was 625,000 . In Manchester, the figure is around $13.5 \%$, or 243,000 . In Birmingham just more than $20 \%$ live in such areas, with a total figure of 337,000 and in Liverpool the comparable figures are $36 \%$ and 391,000 . These data are most striking in the latter two areas and is worth reiterating. In Birmingham's labour market catchment, one fifth of the residents live in an area which is amongst the $10 \%$ most deprived in England and located within a statistically significant larger concentration of deprivation. In Liverpool, more than a third of the population live in such areas.

\section{Table 4 about here}


The findings presented above are not surprising but they begin to tell us much more, in an empirical sense, about the spatiality, intensity and persistence of concentrated deprivation in England. This is also consistent with evidence emerging elsewhere, such as in OAKLEY and LOGAN'S (2007) study of concentrated poverty and affluence in the Bronx, New York. The findings also allow us to comment more rigorously upon the spatial and distributional outcomes (or lack thereof) of the raft of urban policy interventions which have been implemented in recent years, and particularly during the time period covered by the EDI data series. The next section explores such themes and attempts to distil some important messages from the foregoing empirical work.

\section{Discussion}

The focus in this paper has been on assessing spatially concentrated deprivation from an empirical perspective. Now that this has been attempted, it is appropriate to draw together the findings and provide commentary which might help guide future responses to a phenomenon which has come to define some areas of urban England. Three main points are highlighted here. First, the 'persistent significance' of concentrated deprivation is discussed. Second, the spatial variability of concentrated deprivation is suggested as being worthy of greater policy attention. Third, the extent to which a focus on spatially concentrated deprivation as a discrete problem merely obfuscates wider debates about socio-spatial inequality is considered.

\section{The Persistent Significance of Concentrated Deprivation \\ This paper has presented some new evidence on spatially concentrated deprivation for a specific deprivation index. It does, of course, have much wider}


relevance since it describes patterns of socio-spatial inequality found throughout the world. It also follows in the footsteps of previous research which documents the longstanding spatial patterns associated with concentrated deprivation, poverty and disadvantage more broadly (e.g. DORLING et al., 2007). Given the evidence presented in previous research, and the additional spatial intelligence generated here, the contention is that spatially concentrated deprivation can be characterised as exhibiting 'persistent significance' in relation to its spatial statistical manifestation and, concurrently, in relation to its importance as a policy construct. It is a problem which persists spatially and through time but one which, as yet, has not been seriously impacted upon by policies which seek to reduce its intensity.

This view is reinforced when we reconsider ORFORD'S (2004) study of spatial concentrations of urban poverty and affluence in inner London. In this work he identifies a high degree of spatial concentration in relation to a Ward Poverty Index (WPI). This data was constructed for two separate time points nearly one hundred years apart (1896 and 1991) using Census wards, which are significantly larger and more variable in size than LSOAs. Nonetheless, the comparable Moran's I value in both 1896 and 1991 was, remarkably, 0.63 (ORFORD, 2004, 712). Following this, DORLING et al. (2007) explored the spatial concentration of poverty in Britain using their 'breadline poor' and 'core poor' measures for 1970, 1980, 1990 and 2000. The spatial unit here was equivalent to much larger areas (approximately half the size of parliamentary constituencies) but on both measures the global Moran's I values from 1970 to 2000 are in the range of 0.5507 to 0.5952 (DORLING et al., 2007, 37). Finally, SRIDHARAN et al. (2007) explored spatially concentrated deprivation in Scotland using the Carstairs measure of deprivation at postcode sector level and reported a global Moran's I value of 0.5162 (SRIDHARAN et al., 
$2007,1948)$. In this study, the analyses at different spatial scales, from the whole of England to more local labour market areas, has shown a similarly strong degree of spatial concentration of deprivation.

The persistence of spatial concentration through time is perhaps as striking as its intensity but it should not come as a surprise, given what is known about residential sorting (e.g. ROBSON et al., 2008) and inner-city deprivation more generally (e.g. JONES, 1979). What is surprising, or perhaps disappointing, is the degree to which these spatial patterns remain remarkably similar despite successive waves of policy intervention in the most deprived areas. Even where there is some evidence of decreasing spatial concentration (e.g. in Manchester's TTWA) the latest data is still indicative of a socio-spatially divided city, consistent with Wacquant's characterisation of urban areas which contain 'entrenched quarters of misery' (WACQUANT, 1999, 1644). Regardless of one's views on the importance of the neighbourhood effect, the stigmatisation, dislocation and demonization associated with such areas cannot be viewed in a positive light, particularly if it persists through time. Therefore the persistence - and not just the existence - of statistically significant spatial patterns also ought to be given more attention in empirical analyses. In future work, this could be explored under the rubric of what GOODCHILD et al. (1999, 733) refer to as 'spatio-temporal autocorrelation'.

\section{The Spatial Variability of Concentrated Deprivation}

Tobler's famous 'First Law' of geography, where 'everything is related to everything else, but near things are more related than distant things' (TOBLER, $1970,236)$ is often cited as the conceptual underpinning for formal measures of spatial autocorrelation (e.g. MILLER, 2004). Whilst Tobler himself states that he 
does not view this law as being 'literally true' (TOBLER, 2004, 306), it has been an extremely useful point of reference in geographical inquiry. At an aggregate level within England, the potency of the First Law as a general concept is high but when we begin to look at different areas within their local labour market contexts the extent to which the First Law applies begins to vary. In relation to the study of spatially concentrated deprivation, it would seem that 'near things are more related than distant things' within the most deprived labour market areas, and less so elsewhere. Thus, the spatial variability of concentrated deprivation is worthy of further attention since it would appear that the extent to which 'near things are more related than distant things' varies according to deprivation levels within local labour market areas. If this is true, as the evidence suggests, then policies which seek to reduce concentrations of deprivation, for whatever reason, could justifiably be formulated differently based on varying local conditions.

This spatial variability component of concentrated deprivation was brought into sharp focus by the local analyses conducted in the four English TTWAs. Each contains high absolute numbers of residents living in England's most deprived areas but this varies significantly between places. For example, 10.6\% of London's population live in areas among England's most deprived decile, whereas the equivalent figure for Liverpool is $37.8 \%$. In both cases, however, the global Moran's I value was significantly high, indicating a level of spatial polarisation which resonates with WACQUANT'S (1999) conception of 'urban marginality'. What is more surprising, in terms of spatial variability, is the extent to which residents live in areas which can be characterised in empirical terms as spatially 'entrenched' within wider areas of deprivation. Around $36 \%$ of the total population of Liverpool's TTWA live in such areas, compared to around $7 \%$ of the population of London. The variability 
between these two examples is extreme, but it does suggest very different local spatial contexts within which urban policy intervention must operate. The contention here is that such differences - and not merely counts of residents living in 'deprived' areas - must be taken into account at a national level and that more locally sensitive policy mechanisms ought to be developed.

\section{Concentrated Deprivation: Only Half of the Story?}

The final point worth emphasising here, and it is by no means trivial, is the continued focus on concentrated deprivation as the research object. In recent years there has been increasing interest in concentrated affluence (e.g. ST. JOHN, 2002; ORFORD, 2004; CARPIANO et al., 2009) but concentrated deprivation, poverty and disadvantage remain dominant in studies of socio-spatial inequality. This is perhaps not surprising, given the policy-oriented nature of much of the work in this area, but it does call into question the epistemological basis for conclusions reached, and policies developed, when studying what might best be described as only half the story. It also calls into question the formulation of policies which try to mitigate the effects of spatially concentrated deprivation but do not attempt to tackle, or even identify, the root causes of such spatial structures from a macro-level perspective. This research has focused on the analysis of spatially concentrated deprivation from the perspective of an English deprivation measure and has highlighted its persistent significance and spatial variability. What is perhaps more important here is evidence to suggest that there is a pressing need to understand more about concentrated affluence as part of a wider socio-spatial dynamic which also includes concentrated deprivation. This is most forcefully demonstrated in Table 1, which shows that around one quarter of the population live in areas which might be characterised as 
'entrenched quarters of affluence'. A proper recognition of such facts might lead to a more balanced overview of the more general construct of socio-spatial inequality (see LOBAO et al., 2007) within which sits a more nuanced conceptualisation of both concentrated affluence and deprivation. This has not been the intention here but it is an important message nonetheless.

\section{Conclusion}

The purpose of this paper has been to provide a method for assessing the extent to which deprivation is concentrated spatially in England. The data presented above confirm what is already known in a general sense whilst providing a level of spatial statistical accuracy which was previously missing. However, the extent to which the phenomenon of spatially concentrated deprivation more generally is incomplete has also been an important finding here. The original motivation for this paper arose from the fact that, empirically, not enough was known about the true nature of spatial deprivation. What emerges from a closer reading of the literature and of policy responses is that the concept also appears to be incomplete theoretically since it tends to focus on only one half of a much wider socio-spatial phenomenon of which concentrated deprivation is only a part. This two-fold incompleteness - empirical and theoretical - therefore suggests much further work is needed in this area, particularly as it relates to policy formulation and application.

The concept of space has been a particularly important element in understanding deprivation and socio-spatial inequalities more generally. This is true of the research carried out here, but there arises the question of whether such a focus has led to a relative neglect of time in such analyses. The availability of new methods, particularly more sophisticated spatial statistics, has made it possible to 
obtain a new level of understanding in relation to the polarisation of wealth across space. However, a question remains about the importance of variation through space vis-à-vis variation through time. In relation to the former, spatial concentration in urban areas is often high and this may help us identify more clearly areas for policy intervention. However, the lack of variation through time is - perhaps - a more important part of the story here. The current study found little variation throughout a data series of seven years, whereas others found little variation over a period of decades (DORLING et al., 2007) or nearly one century (ORFORD, 2004). This would suggest that whilst spatially concentrated deprivation is a serious policy challenge, the greatest challenge might be temporal rather than spatial. That is, the greatest challenge might be in developing an inter-generational approach to tackling a spatial phenomenon which persists through time. This has not been the task here, but the development of an approach which can measure 'spatio-temporal autocorrelation' would be a good starting point.

Finally, it is worth re-emphasising the extreme spatial variability of concentrated deprivation across England. Even if neighbourhood effects are not used as the theoretical basis for policy intervention, there are surely some more general territorial justice issues associated with such spatial patterns (MORGAN, 2006). If neighbourhood effects do form part of the underlying rationale for policy intervention then the case for taking the spatial variability of concentrated deprivation into account is far greater. As such, a more nuanced policy approach to concentrated deprivation ought to - in addition to the two facets outlined above recognise the importance of localised concentrations within the national context. Cities such as Liverpool and Birmingham, as is well known, contain a disproportionate percentage of England's most deprived residents. The same is true 
of London and Manchester. However, within the former two cities those residents are disproportionately clustered in larger concentrations of deprivation. Now that a formal empirical baseline of such conditions has been laid down, the challenge is to formulate policies which recognise these spatial inequalities and work to reduce them through space and, crucially, over time.

Acknowledgements: I would like to thank the anonymous referees for their helpful comments on an earlier draft of this paper. I would also like to thank colleagues in the Department of Town and Regional Planning at the University of Sheffield for helpful comments on an earlier version of this paper.

\footnotetext{
${ }^{1}$ In line with robust spatial statistical procedures, the Moran's / values reported in this paper are based on a randomization method which uses 999 permutations. This has been performed in order to maximise the numerical stability of the results (see ANSELIN, 2003, 103)

${ }^{2}$ The Economic Deprivation Index, like the Indices of Deprivation, is published at Lower Layer Super Output Area level. These areas, known as LSOAs, have an average population of around 1,500 and the boundaries are consistent through time.

${ }^{3} \mathrm{~A}$ binary first order contiguity matrix was used in this research, using row-standardised spatial weights.

${ }^{4}$ In this study significance values are reported in relation to running 999 permutations since significance in Moran's I is based on a permutation test (see ANSELIN et al, 2004). All values of Moran's / cited in the paper are statistically significant, with $p$-values of $<0.001$ in each case.
} 


\title{
References
}

ANSELIN L. (1995) 'Local Indicators of Spatial Association - LISA', Geographical Analysis, Vol. 27, No. 2, 93-115.

ANSELIN L. (2003) GeoDa 0.9 User's Guide, Center for Spatially Integrated Social Science, Urbana-Champagne.

\begin{abstract}
ANSELIN L., SYABRI I. and KHO Y. (2004) GeoDa: An Introduction to Spatial Data Analysis, University of Illinois, Urbana-Champaign.
\end{abstract}

ARTHURSON K. (2002) 'Creating Inclusive Communities through Balancing Social Mix: A Critical Relationship or Tenuous Link?', Urban Policy and Research, 20( 3), 245-261.

BEYER H. (2010) Geospatial Modelling Environment, Hawthorne Beyer, available at: http://www.spatialecology.com/gme.

BRENNAN A., RHODES J. and TYLER P. (2000) 'The nature of local area social exclusion in England and the role of the labour market', Oxford Review of Economic Policy, 16(1), 129-146.

BROADWAY M. (1989) 'A comparison of patterns of urban deprivation between Canadian and U.S. cities', Social Indicators Research, 21, 531-551. 
BRÜLHART M. and TRAEGER R. (2005) 'An account of geographic concentration patterns in Europe', Regional Science and Urban Economics, 35, 597-624.

CARPIANO R., LLOYD J. and HERTZMAN C. (2009) 'Concentrated affluence, concentrated disadvantage, and children's readiness for school: A population-based, multi-level investigation', Social Science \& Medicine, 69(3), 420-432.

CARSTAIRS V. and MORRIS R. (1991) Deprivation and health in Scotland, Aberdeen University Press, Aberdeen.

CHATTERTON P. and BRADLEY D. (2000) 'Bringing Britain Together? The limitations of area-based regeneration policies in addressing deprivation', Local Economy, 15(2), 98-111.

CHESHIRE P. (2007) Segregated neighbourhoods and mixed communities: a critical analysis, Joseph Rowntree Foundation, York.

CLG [COMMUNITIES AND LOCAL GOVERNMENT] (2007) Place Matters, CLG, London.

CLG [COMMUNITIES AND LOCAL GOVERNMENT] (2009) Tracking Neighbourhoods: The Economic Deprivation Index 2008, CLG, London.

CLG [COMMUNITIES AND LOCAL GOVERNMENT] (2010) Tracking economic deprivation in New Deal for Communities areas, CLG, London. 
CLIFF A. and ORD K. (1970) 'Spatial autocorrelation: a review of existing and new measures', Economic Geography, 46, 269-292.

COHEN D., FARLEY T. and MASON K. (2003) 'Why is poverty unhealthy? Social and physical mediators', Social Science \& Medicine, 57(9), 1631-1641.

COOMBES M., GREEN A. and OWEN D. (1988) 'Substantive issues in the definition of 'localities': evidence from sub-group local labour market areas in the West Midlands', Regional Studies, 22(4), 303-318.

COOMBES M. and BOND S. (2008) 'Travel-to-Work Areas: the 2007 review', Office for National Statistics, London.

COULTON C., CHOW J. WANG E. and SU M. (1996) 'Geographic concentration of affluence and poverty in 100 metropolitan areas, 1990', Urban Affairs Review, 32(2), $186-216$.

DABINETT G. (2010) 'Spatial Justice and the Translation of European Strategic Planning Ideas in the Urban Sub-region of South Yorkshire', Urban Studies, 47(11), 2389-2408.

DANZIGER S. and GOTTSCHALK P. (1987) 'Earnings Inequality, the Spatial Concentration of Poverty, and the Underclass', American Economic Review, 77(2), $211-215$ 
DARCY M. (2007) 'Place and Disadvantage: The Need for Reflexive Epistemology in Spatial Social Science', Urban Policy and Research, 25(3), 347-361.

DEAS I., ROBSON B., WONG C. and BRADFORD M. (2003) 'Measuring neighbourhood deprivation: a critique of the Index of Multiple Deprivation', Environment and Planning C, 21 (6), 883-903.

DORLING D., RIGBY J., WHEELER B., BALLAS D., THOMAS B., FAHMY E., GORDON E., and LUPTON R. (2007) Poverty, wealth and place in Britain, 1968 to 2005, Joseph Rowntree Foundation, York.

DUYVENDAK J., HENDRIKS F., van NIEKERK M. (2009) City in Sight: Dutch Dealings with Urban Change, Amsterdam University Press, Amsterdam.

EVERITT B and HOTHORN T. (2006) A handbook of statistical analyses using $R$, Taylor and Francis, Boca Raton.

FOTHERINGHAM A. and WONG D. (1991) 'The modifiable areal unit problem in multivariate statistical analysis', Environment and Planning A, 23(7), 1025-1044.

GALSTER G. (2005) 'Consequences From the Redistribution of Urban Poverty During the 1990s: A Cautionary Tale', Economic Development Quarterly, 19(2), 119125. 
GALSTER G. (2007) 'Neighbourhood Social Mix as a Goal of Housing Policy: A Theoretical Analysis', International Journal of Housing Policy, 7(1), 19-43.

GALSTER G., MARCOTTE D. E., MANDELL M., WOLMAN H. and AUGUST N. (2007) 'The Influence of Neighbourhood Poverty During Childhood on Fertility, Education and Earnings Outcomes', Housing Studies, 22(5), 723-751.

GOERING J. and FEINS J. (Eds.) (2003) Choosing a better life: Evaluating the Moving to Opportunity social experiment. The Urban Institute, Washington, DC.

GOODCHILD M., EGENHOFER M., KEMP K., MARK D. and SHEPPARD E. (1999) 'Introduction to the Varenius project', International Journal of Geographical Information Science, 13(8), 731-745.

GREEN M. and R. FLOWERDEW R. (1996)' New evidence on the modifiable areal unit problem', in P. LONGLEY and M. BATTY (eds.) Spatial Analysis: Modeling in a GIS Environment, Geolnformation International, Cambridge 41-54.

HARVEY D. (1985) The Urbanization of Capital, Basil Blackwell, Oxford.

JONES C. (Ed.) (1979) Urban deprivation and the inner city, Croom Helm, London.

LAWLESS P. (2004) 'Locating and explaining area-based urban initiatives: New Deal for Communities in England', Environment and Planning C, 22(3), 383-399. 
LOBAO L., HOOKS G. and TICKAMYER A. (Eds.) (2007) The Sociology of Spatial Inequality, State University of New York, Albany.

LORANT V., THOMAS I., DELIEGE D. and TONGLET R. (2001) 'Deprivation and mortality: the implications of spatial autocorrelation for health resources allocation', Social Science and Medicine, 53 (12), 1711-1719.

LUPTON R. and FULLER C. (2009) 'Mixed Communities: A New Approach to Spatially Concentrated Poverty in England', International Journal of Urban and Regional Research, 33(4), 1014-1028.

MARCON E. and PUECH F. (2003) 'Evaluating the Geographic Concentration of Industries Using Distance-Based Methods', Journal of Economic Geography, 3(4), 409-428.

MASSEY D. (1979) 'In What Sense a Regional Problem', Regional Studies, 13, 233243.

MASSEY D. (1996) 'The age of extremes: Concentrated affluence and poverty in the twenty-first century', Demography 33(4), 395-412.

MASSEY D. and EGGERS M. (1993) 'The spatial concentration of affluence and poverty during the 1970s', Urban Affairs Quarterly, 29(2), 299-315. 
MESSER L., LARAIA B., KAUFMAN J., EYSTER J., HOLZMAN C., CULHANE J., ELO I., BURKE J. and CAMPO P. (2006) 'The Development of a Standardized Neighborhood Deprivation Index', Journal of Urban Health, 83(6), 1041-1062.

MILLER H. (2004) 'Tobler's First Law and Spatial Analysis', Annals of the Association of American Geographers, 94(2), 284-289.

MITCHELL A. (2005) The ESRI Guide to GIS Analysis: Volume 2 - Spatial Measurements and Statistics, ESRI Press, Redlands, California.

MORGAN K. (2006) 'Devolution and Development: Territorial Justice and the NorthSouth Divide', Publius, 36(1), 189-206.

NATION M. (2008) 'Concentrated disadvantage in urban neighborhoods: psychopolitical validity as a framework for developing psychology-related solutions', Journal of Community Psychology, 36(2), 187-198.

NOLAN B. and WHELAN C. (2010) 'Using Non-Monetary Deprivation Indicators to Analyze Poverty and Social Exclusion: Lessons from Europe?', Journal of Policy Analysis and Management, 29(2), 305-325.

NORTH D. and SYRETT S. (2008) 'Making the Links: Economic Deprivation, Neighborhood Renewal and Scales of Governance', Regional Studies, 42(1), 133148. 
OAKLEY D. and BURCHFIELD K. (2009) 'Out of the projects, still in the hood: the spatial constraints on public-housing residents' relocation in Chicago', Journal of Urban Affairs, 31(5), 589-614.

OAKLEY D. and LOGAN J. (2007) 'A Spatial Analysis of the Urban Service Landscape: What Accounts for Differences across Neighborhoods?' in LOBAO, L., HOOKS, G. and TICKAMYER, A. (Eds.) Who Gets What Where? The Sociology of Spatial Inequality, State University of New York Press, Albany, NY.

ODPM (2004) The English Indices of Deprivation 2004 (Revised), HMSO, London.

OPENSHAW S. and TAYLOR P. (1979) 'A million or so correlation coefficients', In N. WRIGLEY (Ed.), Statistical Methods in the Spatial Sciences, London, 127-144, Pion.

ORFORD S. (2004) 'Identifying and comparing changes in the spatial concentrations of urban poverty and affluence: a case study of inner London', Computers, Environment and Urban Systems, 28(6), 701-717.

PAMPALON R. and RAYMOND G. (2000) 'A deprivation index for health and welfare planning in Quebec', Health Canada, 21(3), 104-113.

PATACCHINI E. and RICE P. (2007) 'Geography and Economic Performance: Exploratory Spatial Data Analysis for Great Britain', Regional Studies, 41(4), 489508. 
RAE A. (2009) 'Isolated Entities or Integrated Neighbourhoods? An Alternative Approach to the Measurement of Deprivation', Urban Studies, 46(9), 1859-1878.

REY G., JOUGLA E., FOUILLET A. and HÉMON D. (2009) 'Ecological association between a deprivation index and mortality in France over the period 1997 - 2001: variations with spatial scale, degree of urbanicity, age, gender and cause of death', BMC Public Health, 9(33), 1-12.

ROBSON B., LYMPEROPOULOU K. and RAE A. (2008) 'People on the move: exploring the functional roles of deprived neighbourhoods', Environment and Planning A, 40(11), 2693-2714.

SAMPSON R., RAUDENBUSH S. and EARLS F. (1997) 'Neighborhoods and violent crime - a multilevel study of collective efficacy', Science, 277, 1-7.

SAMPSON R., MORENOFF J. and GANNON-ROWLEY T. (2002) 'Assessing Neighborhood Effects: Social Processes and New Directions in Research', Annual Review of Sociology, 28, 443-478.

SAMPSON R. (2003) 'The Neighborhood Context of Well Being', Perspectives in Biology and Medicine, 46, S53-S73.

SRIDHARAN S., TUNSTALL H., LAWDER R. and MITCHELL R. (2007) 'An exploratory spatial data analysis approach to understanding the relationship between deprivation and mortality in Scotland', Social Science \& Medicine, 65(9), 1942-1952. 
ST. JOHN C. (2002) 'The Concentration of Affluence in the United States, 1990', Urban Affairs Review, 37(4), 500-520.

TOBLER W. (1970) 'A Computer Movie Simulating Urban Growth of the Detroit Region', Economic Geography, 46, 234-240.

TOBLER W. (2004) 'On the First Law of Geography: A Reply', Annals of the Association of American Geographers, 94(2), 304-310.

VAN HAM M. and MANLEY D. (2010) 'The effect of neighbourhood housing tenure mix on labour market outcomes: a longitudinal investigation of neighbourhood effects', Journal of Economic Geography, 10(2), 257-282.

VAN KEMPEN R. and BOLT G. (2009) 'Social cohesion, social mix and urban policies in the Netherlands', Journal of Housing and the Built Environment, 24(4), 457-475.

WACQUANT L. (1999) 'Urban Marginality in the Coming Millennium', Urban Studies, 36(10), 1639-1647. 
Figure 1 - Most Deprived and Least Deprived Deciles (EDI, 1999)

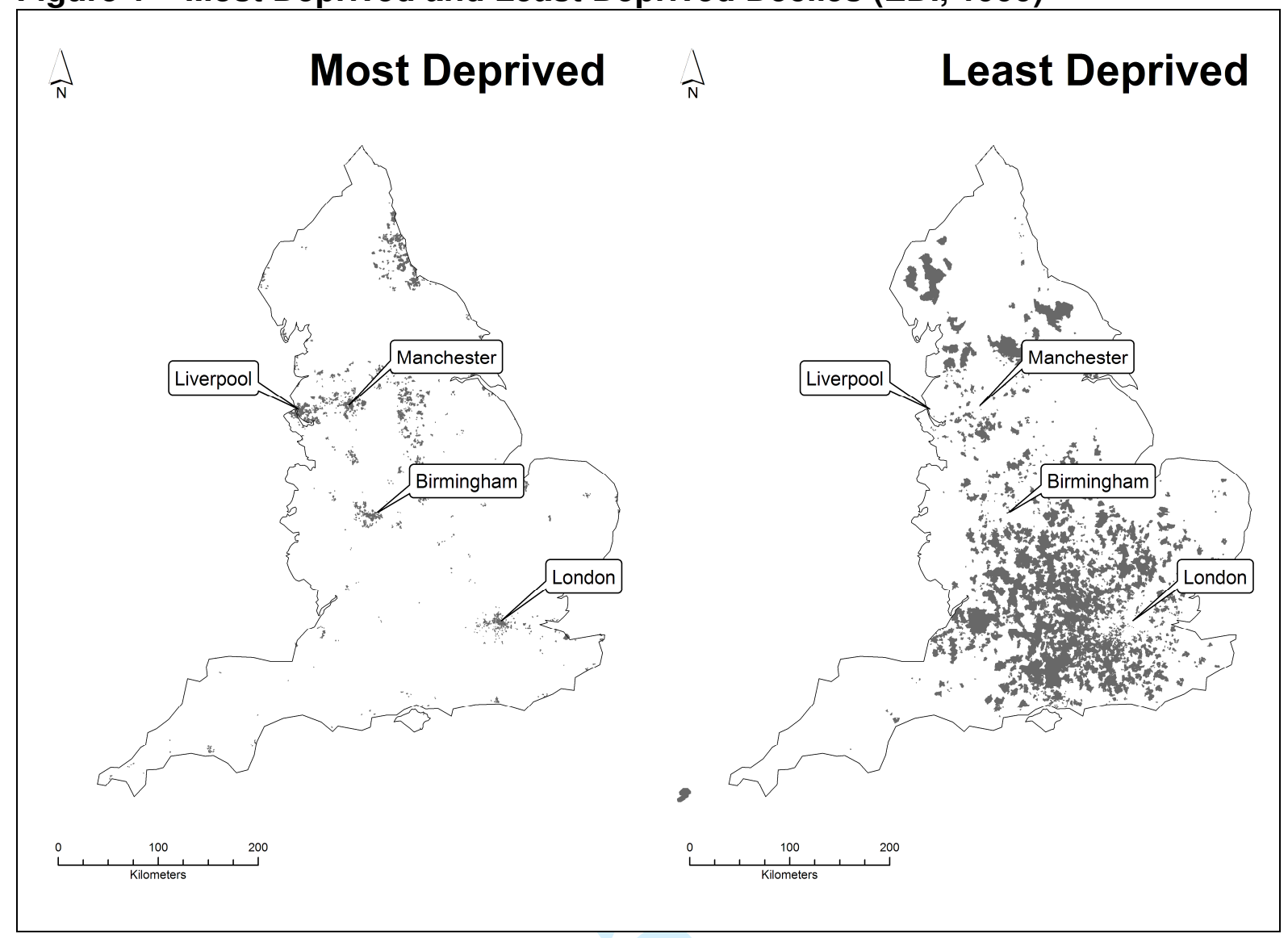


Figure 2 - Global Moran's I Scatterplots 1999-2005
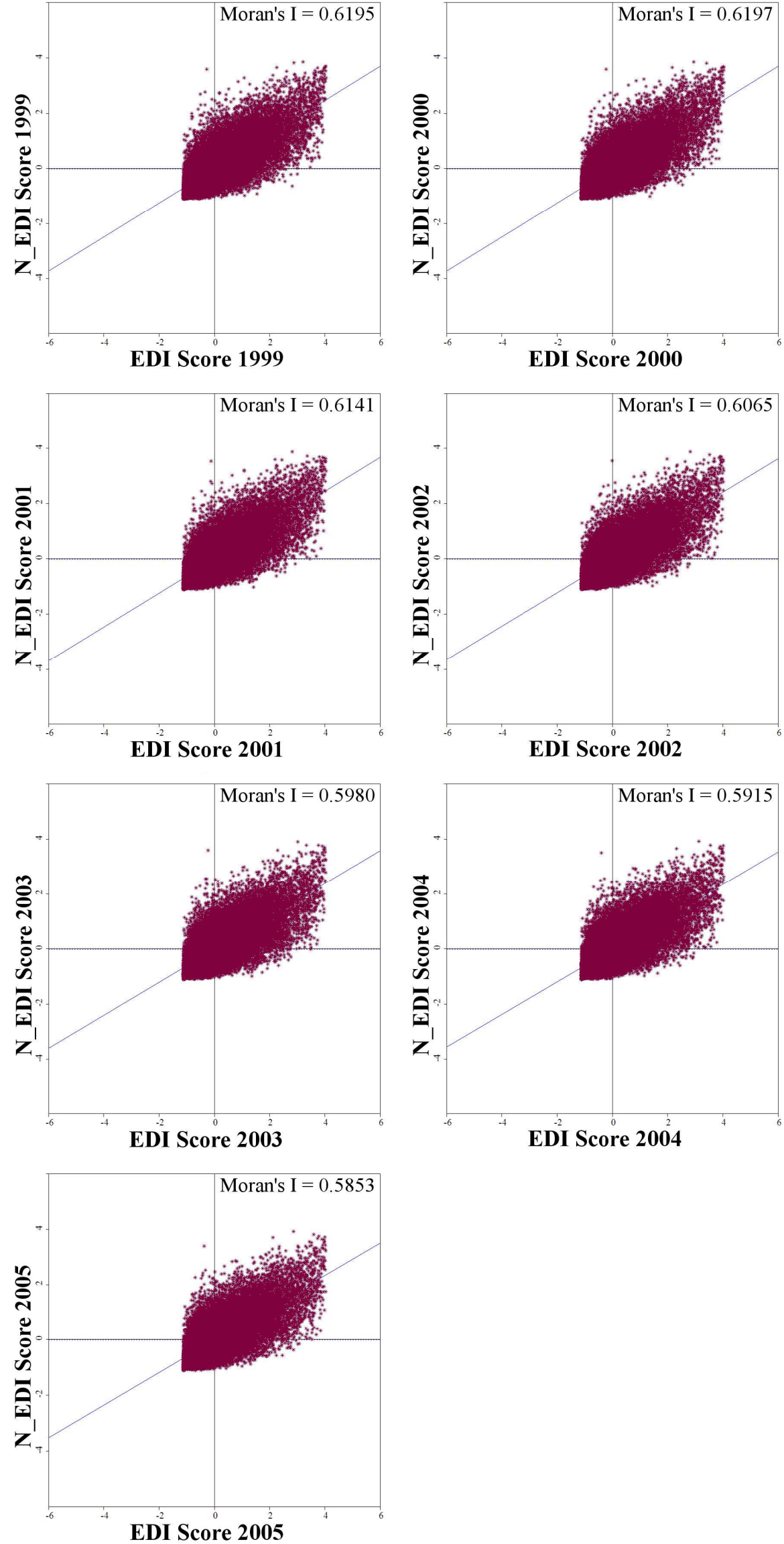

http://mc.manuscriptcentral.com/cres Email: regional.studies@fm.ru.nl 
Figure 3 - Link Between Global Moran Scatterplot and LISA Categories

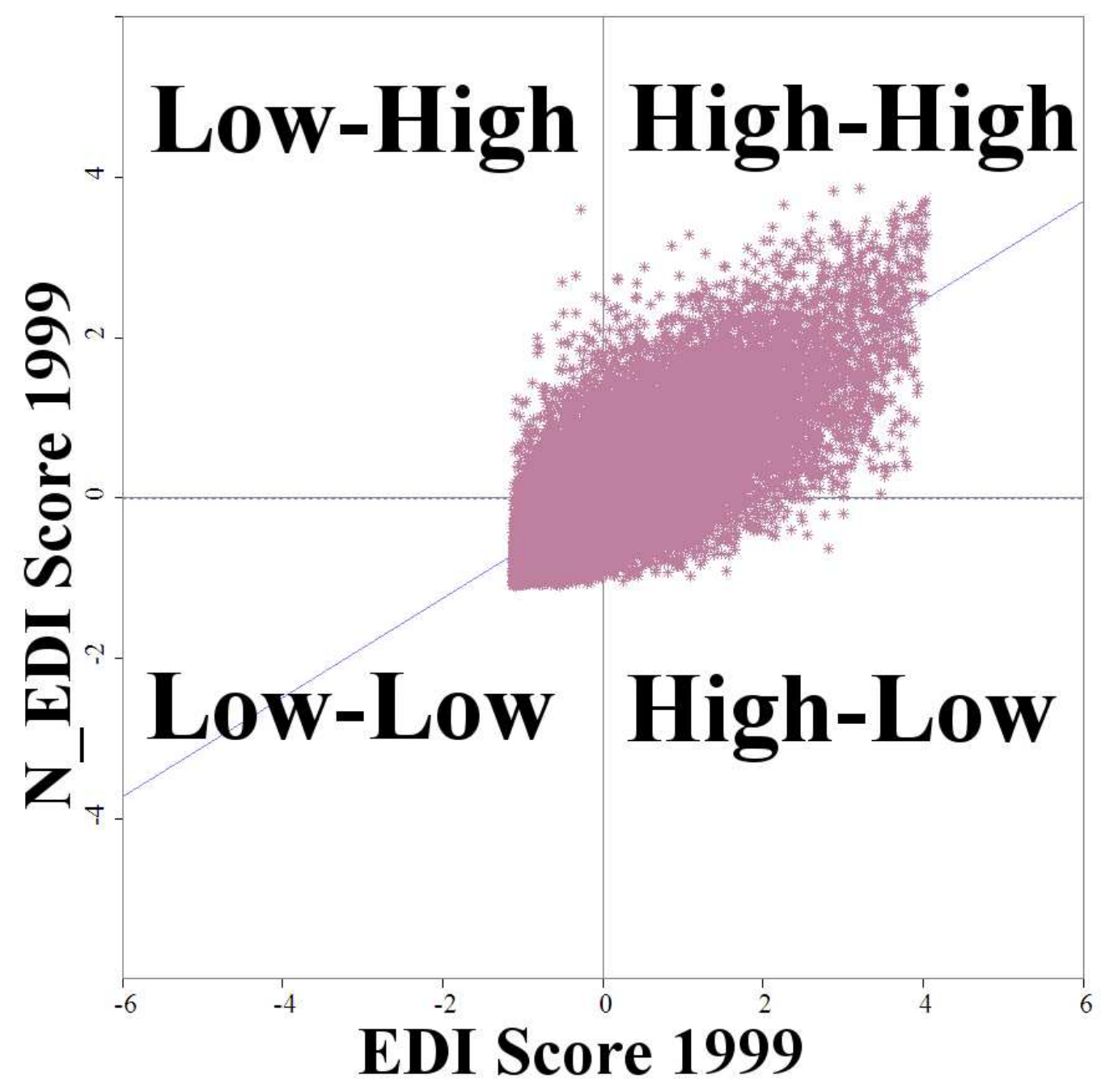


Table 1 - Population of England by LISA Category, 1999 to 2005 (\%)

\begin{tabular}{|c|c|c|c|c|c|c|c|}
\hline Cluster & $\mathbf{1 9 9 9}$ & $\mathbf{2 0 0 0}$ & $\mathbf{2 0 0 1}$ & $\mathbf{2 0 0 2}$ & $\mathbf{2 0 0 3}$ & $\mathbf{2 0 0 4}$ & $\mathbf{2 0 0 5}$ \\
\hline $\begin{array}{c}0 \\
\text { (Not Significant) }\end{array}$ & 57.9 & 58.1 & 58.4 & 58.6 & 58.9 & 59.0 & 58.8 \\
\hline $\begin{array}{c}1 \\
\text { (High-High) }\end{array}$ & 15.0 & 15.0 & 14.8 & 14.7 & 14.5 & 14.5 & 14.6 \\
\hline $\begin{array}{c}2 \\
(\text { Low-Low) }\end{array}$ & 24.8 & 24.6 & 24.4 & 24.1 & 24.0 & 23.9 & 24.0 \\
\hline $\begin{array}{c}3 \\
(\text { Low-High) }\end{array}$ & 1.4 & 1.4 & 1.5 & 1.5 & 1.6 & 1.6 & 1.6 \\
\hline $\begin{array}{c}4 \\
\text { (High-Low) }\end{array}$ & 0.9 & 0.9 & 1.0 & 1.0 & 1.0 & 1.0 & 1.1 \\
\hline Total & $\mathbf{1 0 0 . 0}$ & $\mathbf{1 0 0 . 0}$ & $\mathbf{1 0 0 . 0}$ & $\mathbf{1 0 0 . 0}$ & $\mathbf{1 0 0 . 0}$ & $\mathbf{1 0 0 . 0}$ & $\mathbf{1 0 0 . 0}$ \\
\hline
\end{tabular}


Figure 4 - LISA Category by Deprivation Score, 2005

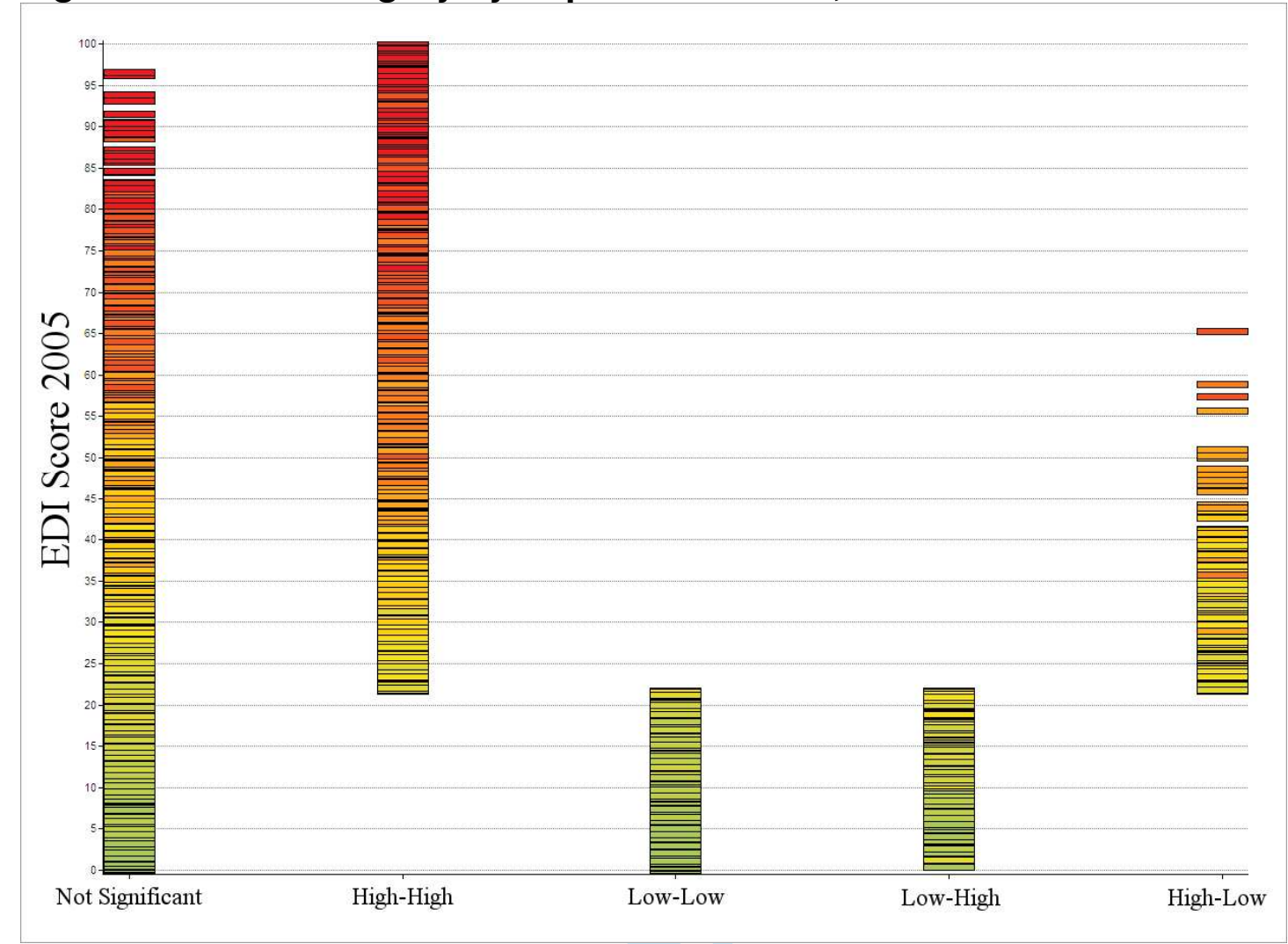


Figure 5 - LISA Category by Deprivation Score, 2005: Most Deprived Decile

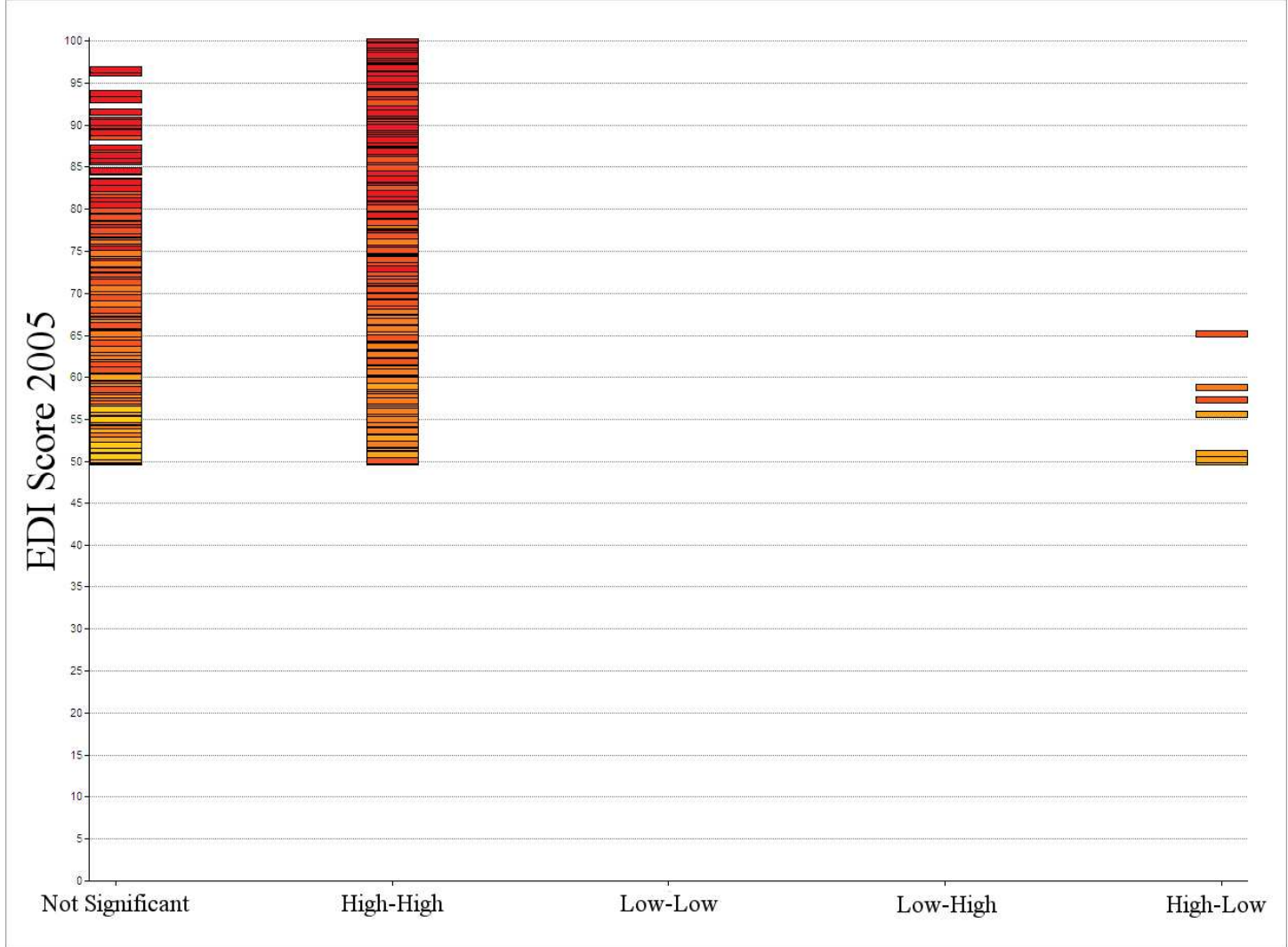


Figure 6 - EDI Score 2005 vs. Local Moran's / 2005

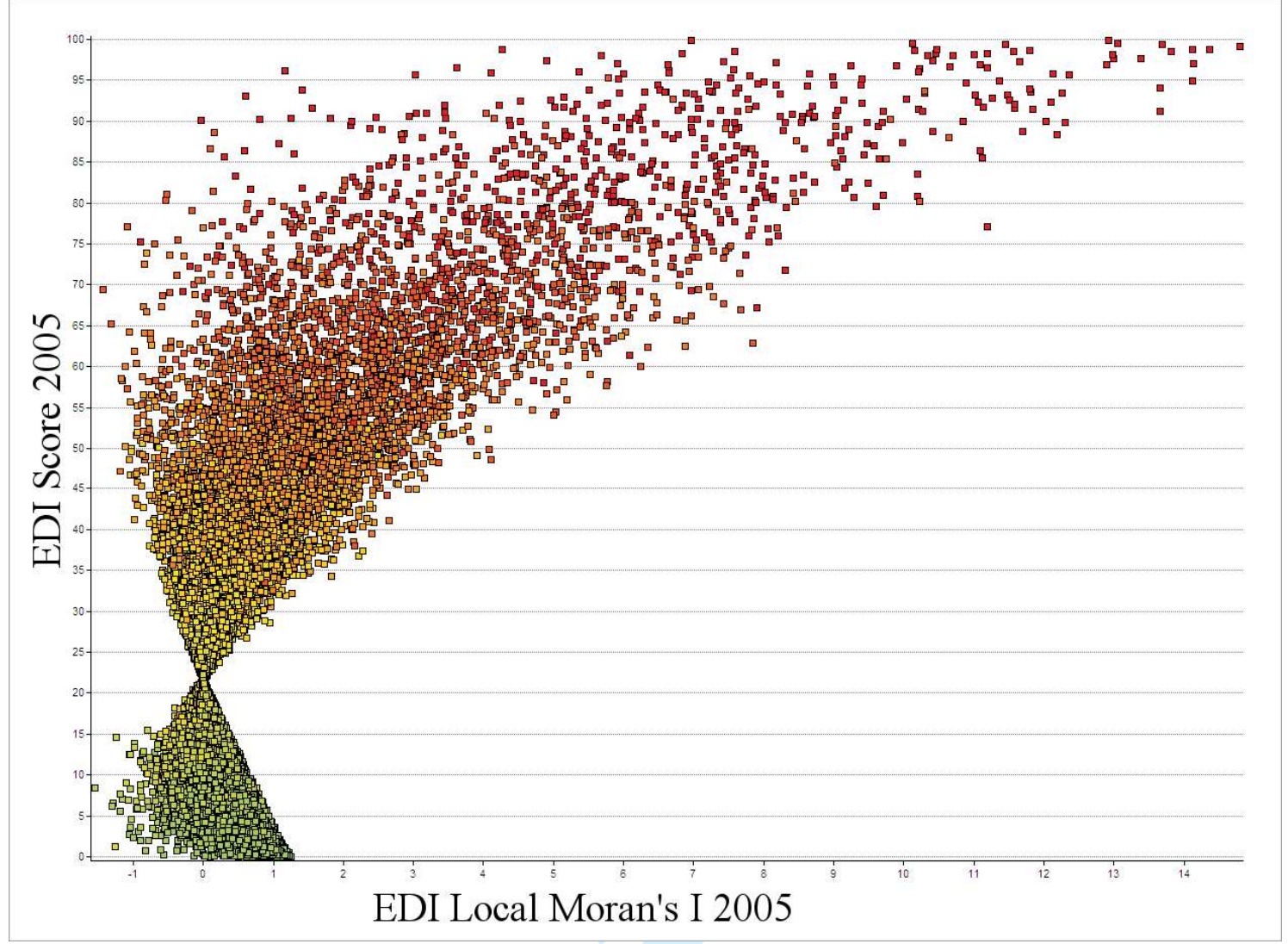


Figure 7 - TTWAs: London, Birmingham, Liverpool and Manchester
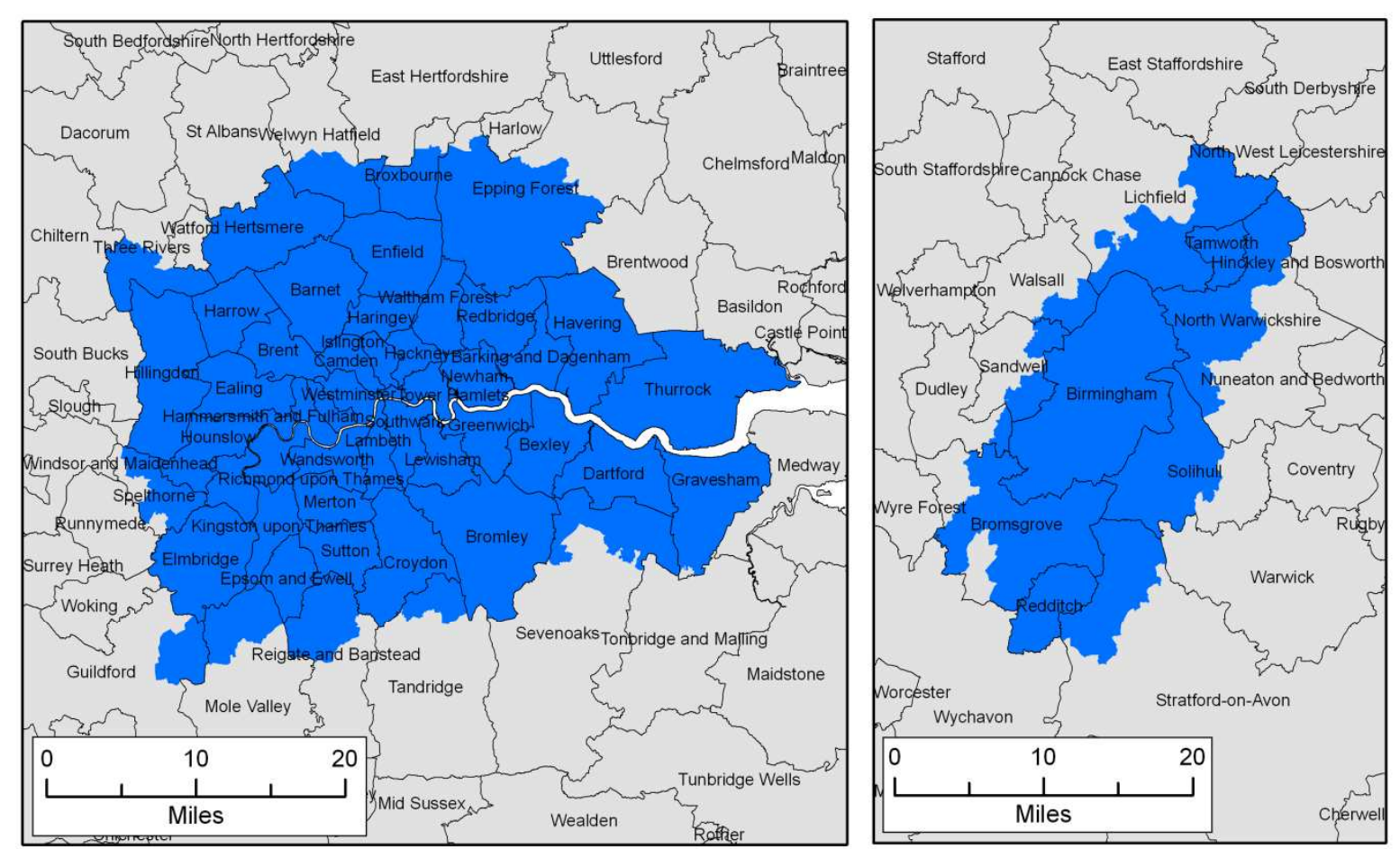

\section{London}

\section{Birmingham}
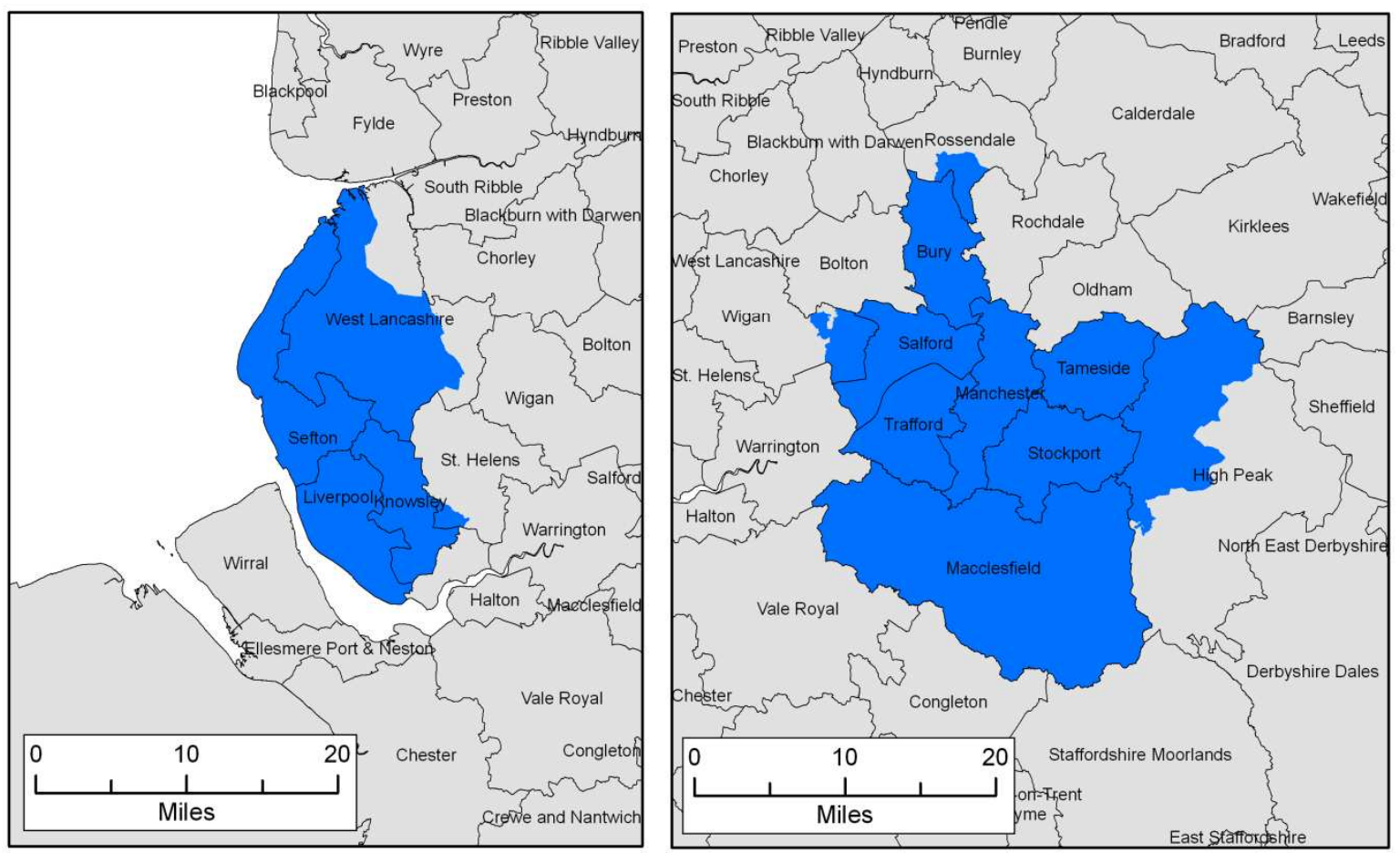

Liverpool

Manchester 
Table 2 - Summary of Population and Deprivation by TTWA, 2005

\begin{tabular}{|l|c|c|c|}
\hline TTWA & Population & $\begin{array}{c}\text { In Most Deprived } \\
\text { EDI Decile }\end{array}$ & $\begin{array}{c}\text { \% of Population in Most } \\
\text { Deprived EDI Decile }\end{array}$ \\
\hline London & $8,533,879$ & 902,558 & 10.6 \\
\hline Manchester & $1,796,583$ & 338,631 & 18.8 \\
\hline Birmingham & $1,615,078$ & 390,556 & 24.2 \\
\hline Liverpool & 962,762 & 364,165 & 37.8 \\
\hline
\end{tabular}


Table 3 - Moran's I Values by TTWAs, 1999-2005

\begin{tabular}{|l|r|r|r|r|r|r|r|}
\hline TTWA & $\mathbf{1 9 9 9}$ & $\mathbf{2 0 0 0}$ & $\mathbf{2 0 0 1}$ & $\mathbf{2 0 0 2}$ & $\mathbf{2 0 0 3}$ & $\mathbf{2 0 0 4}$ & $\mathbf{2 0 0 5}$ \\
\hline London & 0.6341 & 0.6221 & 0.6045 & 0.5979 & 0.5977 & 0.6013 & 0.5955 \\
\hline Birmingham & 0.6402 & 0.6581 & 0.6538 & 0.6455 & 0.6452 & 0.6375 & 0.6307 \\
\hline Manchester & 0.5850 & 0.5740 & 0.5698 & 0.5641 & 0.5564 & 0.5403 & 0.5267 \\
\hline Liverpool & 0.6559 & 0.6597 & 0.6647 & 0.6608 & 0.6568 & 0.6499 & 0.6449 \\
\hline
\end{tabular}


Table 4 - Population (\%) by LISA Cluster Category, Most Deprived Decile

\begin{tabular}{|l|c|c|c|c|c|c|}
\hline & \multicolumn{7}{|c|}{ LISA Cluster Category } \\
\hline & (0) Not Significant & \multicolumn{2}{|c|}{ (1) High-High } & \multicolumn{2}{c|}{ (4) High-Low } \\
\hline TTWA & 1999 & 2005 & 1999 & 2005 & 1999 & 2005 \\
\hline London & 3.6 & 3.2 & 7.1 & 7.3 & 0.1 & 0.0 \\
\hline Manchester & 5.6 & 5.3 & 13.7 & 13.5 & 0.0 & 0.0 \\
\hline Birmingham & 4.4 & 3.3 & 20.3 & 20.9 & 0.0 & 0.0 \\
\hline Liverpool & 1.5 & 2.3 & 36.5 & 35.5 & 0.0 & 0.0 \\
\hline
\end{tabular}

